\section{Cave: Magentabletten bei Schwangeren!}

\begin{abstract}
Nimmt eine werdende Mutter säurehemmende Medikamente ein, werden Allergene in geringerem Maß denaturiert. Ob dies Folgen für ihr Kind hat, untersuchten Autoren in einer großen Populationsstudie.
\end{abstract}

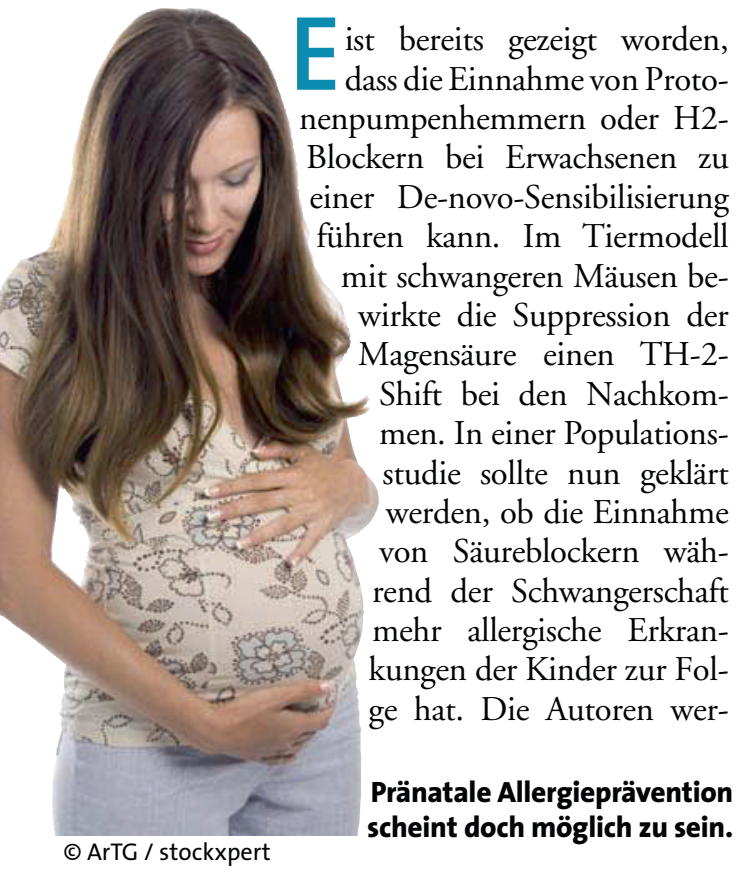

teten dazu die Daten mehrerer schwedischer Gesundheitsregister aus.

Von 585.716 ohne Kaiserschnitt geborenen Kindern wurde im weiteren Verlauf bei 29.490 (5,03\%) entweder eine Allergie diagnostiziert oder es wurden antiallergische Medikamente verschrieben. 5.645 der Kinder wurden von Müttern zur Welt gebracht, die während der Schwangerschaft säurereduzierende Arzneimittel eingenommen hatten. Insgesamt gab es 405 Kinder mit Allergien nach einer entsprechenden Medikation der schwangeren Mutter.

Die Wahrscheinlichkeit einer Allergie war für Kinder von Müttern mit Behandlung durch Säureblocker oder Antazida während der Schwangerschaft signifikant erhöht (Odds Ratio [OR] 1,43; 95\%-Konfidenzintervall [95\%-KI] 1,291,59). Der Zusammenhang bestand un- abhängig davon, welcher Medikamententyp zum Einsatz gekommen war, ob die Substanzen in der frühen oder späten Schwangerschaft eingenommen wurden oder ob die Mutter eine Allergie bei sich selbst angegeben hatte.

Von den 585.716 Kindern entwickelten 3,7\% ein Asthma. Bei Kindern von Müttern mit Einnahme säuresenkender Substanzen in der Schwangerschaft lag dieser Anteil mit 5,6\% signifikant höher (OR 1,51; 95\%-KI 1,351,69). Andere allergische Erkrankungen wie Nahrungsmittelallergien, atopische Dermatitis oder allergische Rhinitis traten nicht signifikant erhöht auf.

Fazit: Kinder, deren Mütter während der Schwangerschaft Magensäure reduzierende Medikamente einnehmen, haben offenbar ein höheres Risiko für Allergien und Asthma bronchiale.

af

Dehlink E et al. First evidence of a possible association between gastric acid suppression during pregnancy and childhood asthma: a population-based register study. Clin Exp Allergy 2009; 39: 246-53

\section{Prävention durch Stillen - ein Experiment}

\author{
Schützt Stillen vor Allergien? Diese Frage beschäftigt Allergologen \\ bereits seit Jahrzenten. Interessante neue Daten hierzu liefert eine \\ deutsche tierexperimentelle Studie.
}

$\mathrm{B}$ ei trächtigen Mäusen erzeugten Forscher aus Hannover im letzten Trimenon durch orale Gabe von Ovalbumin (OVA) oder $\beta$-Lactoglobulin (BLG) eine Toleranz, trächtige Kontrolltiere erhielten oral physiologische Kochsalzlösung. Die Nachkommen wurden nach sechs bis zehn Wochen oder nach vier Monaten intraperitoneal gegen OVA bzw. BLG immunisiert.

Die gegen OVA/BLG sensibilisierten Mäuse-Nachkommen von allergennaiven Müttern zeigten im Metacholinprovokationstest eine erhöhte Atemwegshyperreagibilität, in der Histologie eine eosinophile Atemwegsentzündung, in Zellkulturen aus Splenozyten eine erhöhte Produktion von TH2-Zytokinen sowie erhöhte Serum-IgE-Spiegel. Die
Nachkommen von OVA/BLG-toleranten Mäusen waren dagegen praktisch komplett vor Asthma geschützt, auch wenn sie erst vier Monate nach der Geburt sensibilisiert wurden. Entscheidend für den Schutz war allerdings das Säugen durch die eigene Mutter, nicht tolerante Ammen-Mäuse boten keinen Immunschutz. Allergenspezifisches $\operatorname{Ig}_{1}$ war lediglich in der Milch der allergentoleranten Muttertiere und im Serum der geschützten Jungtiere nachweisbar.

Diese Beobachtung weist darauf hin, dass das allergenspezifische $\operatorname{IgG}_{1}$ vom allergentoleranten Muttertier über die Milch auf die Jungtiere übertragen wird. Die Sensibilisierung der Nachkommen von OVA-toleranten Müttern mit dem heterologen Allergen BLG er- höhte die Immunantwort - sowohl IgE als auch $\operatorname{IgG} \mathrm{G}_{1}$ - gegen dieses Antigen.

Die Umweltbedingungen, denen das Ungeborene über die Mutter während der Gravidität ausgesetzt sind, haben also möglicherweise eine größere Bedeutung als bisher angenommen. Dass dabei sowohl Schutzwirkungen als auch negative Einflüsse zum Tragen kommen, ist wohl eine Erklärung dafür, dass epidemiologische Studien keinen eindeutigen Effekt des Stillens auf das Allergierisiko der Kinder ergeben haben.

Fazit: Ein oral-mukosaler Allergenkontakt in der Gravidität reduziert das Asthma- und Allergierisiko für den Nachwuchs, übertragen wird der Schutz offensichtlich über die Muttermilch. $\quad b k$

Polte T et al. Maternal tolerance achieved during pregnancy is transferred to the offspring via breast milk and persistently protects the offspring from allergic asthma. Clin Exp Allergy 2008; 38: 1950-8 